\title{
Relationship Between Psychiatric Distress and Criminal History Among Intravenous Drug Abusers in Iran
}

\author{
Leyla Sahebi ${ }^{1}$; Mohammad Asghari Jafar Abadi ${ }^{2, *}$; Seyed Hosein Mousavi ${ }^{1}$; Majid Khalili ${ }^{3}$; \\ Maryam Seyedi ${ }^{4}$ \\ ${ }^{1}$ Tabriz Health Service Management Research Center, Tabriz University of Medical Sciences, Tabriz, IR Iran \\ ${ }^{2}$ Department of Epidemiology and Statistics, Road Traffic Injury Prevention Research Center, School of Health, Tabriz University of Medical Sciences, Tabriz, IR Iran \\ ${ }^{3}$ Medical Philosophy and History Research Center, Tabriz University Medical of Sciences, Tabriz, IR Iran \\ ${ }^{4}$ Tuberculosis and Lung Disease Research Center, Tabriz University of Medical Sciences, Tabriz, IR Iran \\ ${ }^{*}$ Corresponding author: Mohammad Asghari Jafar Abadi, Department of Epidemiology and Statistics, Road Traffic Injury Prevention Research Center, School of Health, Tabriz University \\ of Medical Sciences, Tabriz, IR Iran. Tel:+98-4113357582, Fax:+98-4113378093, E-mail: m_asghari862@yahoo.com
}

Received: August 28, 2013; Revised: February 7, 2014; Accepted: January 28, 2015

Background: Sychotropic agents (alcohol, drugs, and illicit substances) have an important effect on the occurrence or exacerbation of psychological and behavioral derangements such as criminal activity and mental abnormalities.

Objectives: The objective was to assess the relationship between psychiatric distress and criminal history among abusers of intravenous drugs, including heroin, benzodiazepine, codeine, cannabis, opium, and ecstasy.

Materials and Methods: Criminal activity history and psychiatric distress were evaluated among intravenous drug abusers in drop-in centers (DIC) (141 subjects) and an outpatient service to delivery methadone to the addicts located in Razy Hospital (Baghdad, Iraq) (120 subjects). Logistic regression analyses using the SPSS for Windows 18.0 were used for analyzing the data.

Results: About $86 \%$ of the intravenous drug abusers had psychiatric distress and $48.2 \%$ had criminal activity history. DIC addicts group had a better mental well-being compared to the other group, but criminal history rate was similar in two groups. In multiple logistic regression, addiction to heroin (odds ratio $[\mathrm{OR}]=1.9,95 \%$ confidence interval $[\mathrm{CI}]: 1.1-4.1$ ), mental disorders $(\beta=0.060, \mathrm{P}=0.026)$, and low level of education was highly related with criminal activity $(\mathrm{OR}=0.17,95 \% \mathrm{CI}: 0.03-0.89)$.

Conclusions: Higher scores in mental well-being questionnaire of DIC addicts suggest the positive effects of psychological interventions. There is a possibility of the involvement of heroin in occurrence of mental disorders and criminal activity. This finding needs further investigations by larger cohort studies.

Keywords: Crime; Questionnaires; Drug Abusers; Mental Health; Psychiatric Distress

\section{Background}

Psychotropic agents (alcohol, drugs, and illicit substances) have an important effect on the occurrence or exacerbation of psychological and behavioral derangements such as criminal activity and mental abnormalities (1-5). In Hemphill and Fisher study, 52\% of psychiatric patients were addicted to at least alcohol or one narcotic agent (6). Similar results have also been reported in several studies from Iran (7-9). Some studies reported that drug abuse is a factor that drives people toward perpetration of crimes, and there is a high correlation between these two variables $(5,10-12)$. In the USA, one study showed that alcohol or drug abusers had a double-chance of committing crimes (6).

An important issue which deserves more investigation is the effect of the type of drug abused and different combinations of drugs on criminal activity and its severity (5). In a study by Hemphill et al., the type of abused drug was influential in the occurrence or sever- ity of the crime (6). Furthermore, Nurco et al. found a significant relationship between heroin addiction and criminal activity (13). Bennett et al. showed that there is a positive linear relationship between multiple drug use and the number of perpetrated crimes too (14). These illegal substances may affect judgment or behavior directly, or they may lead to criminal behavior indirectly, when the addicted individual craves for the abused drugs (15).

There have been very limited studies in Iran on the association between criminal activity and drug abuse. To the best of our knowledge, so far, no study in Iran has been conducted to investigate the correlation between the type of abused substances and criminal activity.

\section{Objectives}

The objective of this study was to investigate the rela-

Copyright ( ) 2015, Mazandaran University of Medical Sciences. This is an open-access article distributed under the terms of the Creative Commons Attribution-NonCommercial 4.0 International License (http://creativecommons.org/licenses/by-nc/4.0/) which permits copy and redistribute the material just in noncommercial usages, provided the original work is properly cited. 
Sahebi L et al.

tionship between the type of abused drugs and criminal activity, the psychological status in drug abusers, psychological interventions performed in drop-in centers (DIC), and the relationship between alcohol consumption and criminal activity.

\section{Materials and Methods}

During the period of the months from September to December 2009, 141 subjects in DIC group and 120 subjects in Razy Hospital (Baghdad, Iraq) group were sampled in East Azerbayjan province, Iran. DIC centers in East Azerbayjan (Tabriz, Maragheh, and Mianeh) consisted of a government center, six private centers, and 10 mobile teams. The services provided by the DIC centers include: 1) admission and examination of the intravenous drug abuser, 2) provision of counseling services, 3) provision of free disposable syringes, 4 ) education of the mode of use of provided syringes and injection method, 5) counseling regarding substitution of methadone therapy for drug injections and its benefits, and 6) education of evidence of unsafe behaviors for prevention of diseases (16). DIC group consisted of intravenous drug abusers serviced by DIC centers.

We sampled all 10 DIC teams in proportion to the approximate number of addicts in region. The method of sampling was convenient and was continued for 4 months. Razy Hospital group consisted of subjects attended to receive methadone. Enrollment criteria for this group consisted of subjects who had been intravenous drug abusers at least during the last 4 months and who had not been subjected to services of DIC centers.

The data collection instruments included a checklist for demographic variables and a structured and trained interview list for drug-related variables and the General Health Questionnaire-28 (GHQ-28). The GHQ-28 was used to assess psychiatric in respondents. This questionnaire was developed by Goldberg and Hillier to screen somatic symptoms, anxiety and insomnia, social dysfunction, and severe depression. A review of studies on the validation of the GHQ-28 in different countries demonstrates its high validity and reliability as a screening tool of mental well-being in the community. This questionnaire was translated into the official language of Iran (Persian), which is comprehensible to almost every Iranian, and its validity and reliability were approved in previous independent studies $(15,17)$. The estimated intra-class correlation between the test-retest scores was $0.84,0.85$, $0.79,0.88$, and 0.91 for physical condition, anxiety, social dysfunction severe depression, and total score, respectively (18). For each item, four possible answers are available; 1: not all (score $=0$ ), 2: no more than usual (score $=1)$, 3: rather more than usual (score $=2$ ), and 4 : much more than usual (score $=3$ ). The score for subscales and total score were computed by summing over ranks in related items. For each item, including physical condition, anxiety, and social dysfunction subscales there were sev- en questions, and hence the possible range of scores for them is $0-21$. For total score, the possible range would be 0 - 84. Likert scoring method of GHQ showed a cutoff point of 23 (scores higher than 23 indicate a mental disorder). The sensitivity, specificity, and the overall misclassification rates are of $70.5 \%, 92.3 \%$, and $12.3 \%$, respectively $(15,18)$.

Data collection was performed by face-to-face interviewing with the help of a psychologist and each center's head, who was a rehabilitated ex-addict (in order to have a good communication potential with the drug abusers). The interviewers had been totally trained by a physician and an epidemiologist. Furthermore, a gift was offered to each drug abuser in order to motivate the addicted patient for cooperation.

All analyses were performed using SPSS for Windows 18.0 (SPSS Inc., Chicago, IL, USA). Data were presented as mean with a standard deviation (SD) or $95 \%$ confidence interval (CI) and frequency (percent) for quantitative and qualitative variables, respectively. The mean score of the GHQ-28 subscales and its total score was compared between DIC and Razy centers using independent samples t-tests. Univariate and multiple logistic regression analyses were performed to assess the relationship between psychiatric distress and subjective report of criminal activity with controlled type and number of abused substance, use of alcohol and demographical variables. In this approach, significant variables in the univariate analyses were candidate to enter in the multivariate analysis. Some variables were deleted due to low number of the observations in some of their categories. Odds ratios (OR's) and their 95\% Cl's were presented as the effect size of the relationships. P value $<0.050$ was considered as statistically significant.

\section{Results}

Average age of intravenous drug abusers was 27.9 years $(95 \% \mathrm{CI}=26.57-29.35)$ in DIC centers and 28.1 years $(95 \%$ $\mathrm{CI}=26.64$ - 29.42) in Razy Hospital. Women constituted a very small percentage of the studied cases: only 4 (3.3\%) and $2(1.6 \%)$ of the sample in DIC centers and Razy Hospital, respectively. The most common occupation groups in both groups (DIC centers and Razy Hospital) were unskilled and semi-skilled workers, who constituted 78 (60.5\%) and 58 (50.0\%) of the drug abusers, respectively. It is noteworthy that $24(18.6 \%)$ and 34 (29.3\%) of the drug abusers were unemployed in DIC centers and Razy Hospital groups, respectively. Forty (29.6\%) of the addicts in the DIC group and 44 (36.7\%) of the Razy Hospital group had education levels of primary school or lower. As for the marital status, 90 (64.7\%) drug abusers in DIC group and 80 (66.7\%) drug abusers in Razy Hospital group were single. Unprotected (and of course extramarital) sexual relationship among single drug abusers occurred in 39 people $(22.9 \%)$ and the average number of intercourses in the last 30 days was 4.8 times $(S D=5.6)$. It is noteworthy 
Sahebi L et al.

that 35 (20.5\%) of the single drug abusers declined to answer this question.

Self-reported alcohol consumption was 78 (57.8\%) in DIC group, which was higher than Razy Hospital group (15 subjects; $12.6 \%)(\chi 2=55.6, \mathrm{P}<0.001)$. The average amount of alcohol consumption among alcoholic cases was 4.3 (SD = 4.9) glasses per day. In DIC and Razy Hospital groups, this average was 4.5 glasses $(\mathrm{SD}=4.8)$ and 3.3 glasses $(\mathrm{SD}=5.4)$ respectively $(\mathrm{t}=4.6, \mathrm{P}<0.001)$.

One sample t-test was used to compare the status of drug abusers regarding psychiatric distress variables. Drug abusers in DIC centers group and Razy Hospital group were different in all four aspects of psychological health in a statistically significant manner (all $\mathrm{P}<$ 0.050 ) (Table 1). Based on the cut-off point of score 23 for identifying subjects with mental illness, 76.2\% (96 subjects) of DIC subjects and 95.5\% (107 subjects) of Razy Hospital subjects did not have evidence of mental wellbeing $(\mathrm{P}<0.001)$.

In this study, the self-reported rate of criminal activity in intravenous drug abusers was $48.3 \%$ (126 cases). The most frequent crime types associated with other crimes were selling illicit drugs (44 subjects, 40\%), theft (30 subjects, $27.4 \%$ ), and violence (24 subjects, $21.8 \%$ ). Counterfeit- ing, forgery, and check fraud being an accessory to murder, selling and possession of firearms and rape consisted $10.8 \%$ of the crimes reported by respondents ( 12 subjects). Frequency distribution of the type of addiction (heroin, benzodiazepine, codeine, hashish, and opium) according to the committed crimes among intravenous drug abusers is available in Table 2.

In order to investigate variables related with criminal activity, a univariate multiple regression test (unadjusted analysis) was performed initially. Illiterate or low-educated drug abusers had a higher rate of crime perpetration than drug users with an education level of graduated university ( $\mathrm{OR}=4.76, \mathrm{P}=0.021)$. Furthermore, heroin abusers and drug abusers without mental well-being had a higher rate of committing crimes (OR $=2.5, \mathrm{P}=0.002)$ and $(\mathrm{OR}=1.05, \mathrm{P}=0.017)$. Test results are shown in Table 3.

For studying the factors involved in criminal history in the presence of possibly confounding variables, multiple regression test (adjusted analysis) was used. In this model, chance of criminal activity was higher in lower educated abusers, in heroin abusers and abusers without mental well-being $(\mathrm{OR}=5.9, \mathrm{P}=0.036 ; \mathrm{OR}=2.1, \mathrm{P}=0.049$ and, $\mathrm{OR}=1.16, \mathrm{P}=0.026$, respectively) (Table 3 ).

Table 1. Comparison of General Health Questionnaire-28 Total and Subscales Scores Between Two Groups of Intravenous Drug Abusers Studied in Drop-in Centers and Razy Clinic ${ }^{\text {a }}$

\begin{tabular}{lccc}
\hline General Health Question & DIC $^{b}$ & Razy Hospital & P Value \\
\hline Somatization & $10.01 \pm 5.43$ & $10.82 \pm 4.72$ & 0.0230 \\
\hline Anxiety & $11.35 \pm 5.50$ & $12.37 \pm 4.86$ & 0.0010 \\
\hline Social dysfunction & $09.37 \pm 6.05$ & $12.26 \pm 4.04$ & 0.0001 \\
\hline Depression & $10.84 \pm 6.90$ & $13.38 \pm 5.17$ & 0.0001 \\
\hline GHQ $^{\mathrm{C}}$ total score & $42.06 \pm 20.78$ & $49.14 \pm 14.57$ & 0.0010 \\
\hline
\end{tabular}

a Data are presented as Mean \pm SD

b Drop-in centers.

c General Health Questionnaire.

Table 2. Frequency Distribution of the Type of Addiction According to the Committed Crime Among Intravenous Drug Abusers ${ }^{\mathrm{a}}$

\begin{tabular}{lcccc}
\hline Abused drug & \multicolumn{3}{c}{ Crime } \\
\cline { 2 - 5 } & Sale of Illicit Drugs & Theft and Forgery & Violence & Sale of Drugs, Theft, or Violence \\
\hline Heroin & $7(31.8)$ & $7(31.8)$ & $5(22.7)$ & $3(13.6)$ \\
Benzodiazepines & $10(50.0)$ & $4(20.0)$ & $3(15.0)$ & $3(15.0)$ \\
Codeine & - & - & - & - \\
Cannabis & $15(38.5)$ & $12(30.8)$ & $6(15.4)$ & $6(15.4)$ \\
Opium & $17(53.1)$ & $3(9.4)$ & $8(25.0)$ & $4(12.5)$ \\
\hline
\end{tabular}

a Data are presented as NO. (\%). 
Table 3. Relationship Between Some Demographic and Drug Related Variables With Criminal History Based on Uni- and Multi-Variate Analyses ${ }^{a}$

\begin{tabular}{|c|c|c|c|c|c|c|}
\hline \multirow{2}{*}{$\begin{array}{l}\text { Variables and its cofactors: } \\
\text { NO.(\%) }\end{array}$} & \multicolumn{3}{|c|}{ Unadjusted Analysis } & \multicolumn{3}{|c|}{ Adjusted Analysis } \\
\hline & $\mathbf{P}$ & $\mathbf{O R}^{\mathrm{b}}$ & $\mathrm{CI}^{\mathrm{C}}$ & $\mathbf{P}$ & OR $^{b}$ & $\mathrm{CI}^{\mathrm{C}}$ \\
\hline \multicolumn{7}{|l|}{ Group } \\
\hline DIC $^{\mathrm{d}}: 141(54)$ & & 1.00 & & & & \\
\hline Razy clinic: 120 (46) & 0.820 & 0.94 & $0.58-1.50$ & - & - & - \\
\hline Age & 0.880 & - & - & - & - & - \\
\hline \multicolumn{7}{|l|}{ Marital status } \\
\hline Married:170 (65.6) & & 1.00 & & & & \\
\hline Single: 89 (34.4) & 0.230 & 0.73 & $0.43-1.20$ & - & - & - \\
\hline \multicolumn{7}{|l|}{ Educational status } \\
\hline$\leq$ Primary: 84 (32.9) & & 1.00 & & & 1.00 & \\
\hline Middle: 83 (32.9) & 0.140 & 0.63 & $0.34-1.17$ & 0.069 & 0.49 & $0.24-1.10$ \\
\hline High school: 73 (28.6) & 0.610 & 0.85 & $0.45-1.60$ & 0.570 & 0.80 & $0.37-1.70$ \\
\hline Graduated university: 15 (5.9) & 0.021 & 0.21 & $0.54-0.79$ & 0.036 & 0.17 & $0.03-0.89$ \\
\hline \multicolumn{7}{|l|}{ Job } \\
\hline Unskilled worker: 136 (55.5) & 0.190 & 1.00 & $0.79-2.80$ & 0.160 & 1.00 & $0.79-3.90$ \\
\hline Skilled worker: 52 (21.5) & 0.160 & 1.50 & $0.85-2.90$ & 0.800 & 1.80 & $0.43-1.90$ \\
\hline Unemployed: 58 (23.7) & & 1.60 & & & 0.94 & \\
\hline $\mathrm{GHQ}^{\mathrm{e}}$ & 0.017 & 1.05 & $1.01-1.09$ & 0.026 & 1.16 & $1.10-1.12$ \\
\hline \multicolumn{7}{|l|}{ Alcohol use } \\
\hline \multicolumn{7}{|l|}{ No:161(63.4) } \\
\hline Yes: 93 (36.6) & 0.540 & 1.70 & $0.70-1.95$ & - & - & - \\
\hline Rate of alcohol use & 0.065 & 1.08 & $0.98-1.19$ & 0.230 & 1.07 & $0.90-1.20$ \\
\hline \multicolumn{7}{|l|}{ Left drug by methadone } \\
\hline No: $110(42.8)$ & 0.460 & 1.00 & & & & \\
\hline Yes:147 (57.2) & & 1.40 & $0.84-2.30$ & - & - & - \\
\hline \multicolumn{7}{|l|}{ Previous addiction } \\
\hline \multicolumn{7}{|l|}{ Hashish } \\
\hline No:153(59.3) & & 1.00 & & & & \\
\hline Yes: $105(40.7)$ & 0.810 & 1.06 & $0.65-1.75$ & - & - & - \\
\hline \multicolumn{7}{|l|}{ Opium } \\
\hline No: $166(64.3)$ & & 1.00 & & & & \\
\hline Yes: $92(35.7)$ & 0.280 & 0.72 & $0.43-1.20$ & - & - & - \\
\hline \multicolumn{7}{|l|}{ Benzodiazepines } \\
\hline No: $213(82.6)$ & & 1.00 & & & & \\
\hline Yes: $45(17.4)$ & 0.250 & 1.50 & $0.77-2.80$ & - & - & - \\
\hline \multicolumn{7}{|l|}{ Heroin } \\
\hline No: $175(67.8)$ & & 1.00 & & & & \\
\hline Yes: $83(32.2)$ & 0.910 & 1.00 & $0.67-1.70$ & - & - & - \\
\hline \multicolumn{7}{|l|}{ Current addiction } \\
\hline \multicolumn{7}{|l|}{ Hashish } \\
\hline No: $221(87.7)$ & & 1.00 & & & 1.00 & \\
\hline Yes: $31(12.3)$ & 0.130 & 0.29 & $0.60-1.60$ & 0.210 & 0.34 & $0.06-1.90$ \\
\hline
\end{tabular}


Sahebi L et al.

\begin{tabular}{|c|c|c|c|c|c|c|}
\hline No: $242(96.4)$ & & 1.00 & & & 1.00 & \\
\hline Yes: $9(3.6)$ & 0.028 & 0.40 & $0.18-0.90$ & 0.330 & 0.58 & $0.19-1.70$ \\
\hline \multicolumn{7}{|l|}{ Ecstasy } \\
\hline No: $207(82.1)$ & & 1.00 & & & & \\
\hline Yes: $12(4.8)$ & 0.910 & 1.10 & $0.34-3.50$ & - & - & - \\
\hline \multicolumn{7}{|l|}{ Benzodiazepines } \\
\hline \multicolumn{7}{|l|}{ No: $207(82.1)$} \\
\hline Yes: 45 (17.9) & 0.890 & 1.04 & $0.55-1.90$ & - & - & - \\
\hline \multicolumn{7}{|l|}{ Heroin } \\
\hline No: 69 (27.4) & & 1.00 & & & 1.00 & \\
\hline Yes: $183(72.6)$ & 0.002 & 2.50 & $1.40-4.50$ & 0.050 & 2.10 & $1.10-4.20$ \\
\hline \multicolumn{7}{|l|}{ Type of previous addiction } \\
\hline Single drug: 196 (76.3) & & 1 & & & & \\
\hline Multiple drugs: 61 (23.7) & 0.370 & 1.30 & $0.73-2.30$ & - & - & - \\
\hline \multicolumn{7}{|l|}{ Type of current addiction } \\
\hline \multicolumn{7}{|l|}{ Single drug: 185 (73.4) } \\
\hline Multiple drugs: 67 (26.6) & 0.540 & 0.84 & $0.48-1.50$ & - & - & - \\
\hline
\end{tabular}

\section{Discussion}

In the present study, over $85 \%$ (248) of the drug abusers did not have a mental well-being. This rate was $72 \%$ in American intravenous drug abusers and 61.3\% in Australian intravenous abusers $(4,19)$. Overall, the low rate of mental well-being was compatible with other similar studies $(1-5,20)$. According to the results of some other studies, about $50 \%$ of the USA population had comorbid mental disorder and drug abuse $(21,22)$. Furthermore, about $30-50 \%$ of psychiatric patients in clinical centers were also drug abusers (23).

Almost half of intravenous drug abusers had a selfreported history of crime. This result was similar to performed studies in this field $(3,7,8)$. Furthermore, concomitant addiction to both narcotics and alcohol did not increase the chance of criminal activity. On the other hand, some studies $(14,15)$ reported that the probability of criminal activity is higher in the case of multiple drug use. Chaiken et al. (24) also reported that the rate of criminal activity in multiple drug users in the USA was 10 - 20 times higher than the rest of drug abusers (15). In addition, Bennett and Holloway showed that abusers who used either cocaine or crack in Los Angeles had a lower criminal activity rate than abusers who used both cocaine and crack. Furthermore, in a study by Bennett et al. in the UK (14), drug abusers who used both heroin and cocaine had higher levels of illegal income than others but, in the present study, multiple drug use in the presence of confounding variables was not related to the his- tory of criminal activity. Probably this inconsistency is due to differences in culture and lifestyle of the various communities.

In the present study, after control of confounding variables, heroin addiction always increased the chance for criminal activity. The findings of available studies also show that the particular drug type combinations are also influential in criminal activity $(14,15)$, and research reports show that investigation of the relationship between crime and particular drug type combinations provides valuable information for anti-drugs strategies and treatment services (15).

In this regard, the most important factors are economic factors (cost of drugs), lifestyle, and psychopharmacological factors (14). It has been reported that various pharmaceutical combinations may cause higher levels of violence due to their chemical nature (14). In this study, in the presence of confounding variables drug abusers with the lowest level of education had higher chances of committing crimes than drug abusers with higher levels of education. According to the study by Icli et al. (22) low education, and lack of occupational skills, and drug abuse have a direct correlation with criminal activity (22). It seems that high educational level has been associated with the high of awareness of the obscenity crime consistently.

This study due to strength of interviewer's good communication (cooperation with psychologists and reha- 
bilitated ex-addict), had a high accuracy. Modeling and control of confounding variables was of strength of the study, but low number of the participants and restriction in generalizability are limitations of this study.

This study depicted heroin as a dangerous abuse substance that has a strong relationship with the chance of committing a criminal activity. Heroin abusers in DIC centers had higher levels of mental illnesses, while psychiatric distress had no relationship with criminal activity. As a result, it seems that psychiatric distress is an interaction factor in the effect of heroin on criminal history. This implies a probability of psychopharmacological effect of heroin in the occurrence of mental disorders and the likelihood of criminal activity.

\section{Acknowledgements}

The authors would like to express their gratitude to the National Public Health Management Center for financial support, Dr. Ghasem Kiani Moghaddam, Dr. Ali Seidi, Head of Razy Hospital, Dr. Shahram Ghorbani, Head of DIC Centers, the esteemed psychologists of Razy Hospital, liaison agents of DIC Centers for their cordial cooperation, and East Azerbaijan Welfare Organization. The authors also commemorate the late Eng. Haj-Alilu who performed the required coordination for implementing this study in the Welfare Organization.

\section{Authors' Contributions}

Leyla Sahebi conceived and designed the study and drafted the manuscript. Mohammad Asghari Jafar Abadi helped in statistical analysis and project. Seyed Hosein Mousavi cooperated in data collection and communication with the Welfare Organization. Majid Khalili helped to draft the manuscript and English editing. Maryam Seyedi helped to revise the manuscript. All authors read and approved the final manuscript.

\section{Declaration of Interest}

None declared.

\section{References}

1. Gillet C, Polard E, Mauduit N, Allain H. [Acting out and psychoactive substances: alcohol, drugs, illicit substances]. Encephale. 2001;27(4):351-9.

2. Ahmad Vand M, Ghoreishi FS, Sepehmanesh Z, Mousavi GA. [Effect of intravenous drug abusers and methadone in prison.]. $J$ Res Behav Sci. 2006;2(1-2):77-82.

3. Ahmad Vand M. [Addiction and its etiology.].Tehran, Iran: Payam-
Noor University; 1998.

4. De Alba I, Samet JH, Saitz R. Burden of medical illness in drugand alcohol-dependent persons without primary care. Am J Addict. 2004;13(1):33-45.

5. Poldrugo F. Alcohol and criminal behaviour. Alcohol Alcohol 1998;33(1):12-5.

6. Hemphill RE, Fisher W. Drugs, alcohol and violence in 604 male offenders referred for inpatient psychiatric assessment. SAfrMed J. 1980;57(7):243-7.

7. Lundgren LM, Amodeo M, Chassler D. Mental health status, drug treatment use, and needle sharing among injection drug users. AIDS Educ Prev. 2005;17(6):525-39.

8. Hasan Shahi MM, Ahmadian K. [Mental health of psychoactive substance-dependent patients.]. J Fundam Ment Health. 2004;6(23-24):131-9.

9. Sahebi L, Vahidi RGH, Ali-Hoseini S, Mousavi SH. [General health status of injection drug addicts in Drop in centers (DIC) of East Azerbaijan.]. J Fundam Ment Health. 2010;12(3):584-94.

10. Gruenewald PJ, Johnson FW, Ponicki WR, Lascala EA. A dose-response perspective on college drinking and related problems. Addiction. 2010;105(2):257-69.

11. Kosten TR, Rounsaville BJ. Psychopathology in opioid addicts. Psychiatr Clin North Am. 1986;9(3):515-32.

12. Tobin KE, Latkin CA. The relationship between depressive symptoms and nonfatal overdose among a sample of drug users in Baltimore, Maryland. J Urban Health. 2003;80(2):220-9.

13. Nurco DN, Ball JC, Shaffer JW, Hanlon TE. The criminality of narcotic addicts. J Nerv Ment Dis. 1985;173(2):94-102.

14. Bennett T, Holloway K. The association between multiple drug misuse and crime. Int $J$ Offender Ther Comp Criminol. 2005;49(1):63-81.

15. Noorbala AA, Bagheri Yazdi SA, Yasamy MT, Mohammad K. Mental health survey of the adult population in Iran. Br J Psychiatry. 2004;184:70-3.

16. Rasulzadeh M. [The opening of the DIC center in Mianeh.] Ghaflan. 2006;1(2):6-7.

17. Noorbala AA, Bagheri yazdi SA, Mohammad K. [The validation of general health questionnaire- 28 as a psychiatric screening tool.] . Hakim Res J. 2009;11(4):47-53.

18. Sahebi L, Vahidi R, Ayatollahi T. Mental health status of hospitals staff in iran. Res J Biol Sci. 2007;2:743-8.

19. Hickie IB, Koschera A, Davenport TA, Naismith SL, Scott EM. Comorbidity of common mental disorders and alcohol or other substance misuse in Australian general practice. Med J Aust. 2001;175 Suppl:S31-6.

20. Nunes EV, Levin FR. Treatment of depression in patients with alcohol or other drug dependence: a meta-analysis. JAMA. 2004;291(15):1887-96.

21. Grant BF, Stinson FS, Dawson DA, Chou SP, Dufour MC, Compton $\mathrm{W}$, et al. Prevalence and co-occurrence of substance use disorders and independent mood and anxiety disorders: results from the National Epidemiologic Survey on Alcohol and Related Conditions. Arch Gen Psychiatry. 2004;61(8):807-16.

22. Icli TG, Seydiogullari I, Tatlidil H, Coban S, Sever H, Sueroglu U. Profiling property criminals in Turkey. Int J Offender Ther Comp Criminol. 2010;54(4):640-55.

23. Cottencin O. [Severe depression and addictions]. L'Encephale. 2009;35:S264-8.

24. Chaiken JM, Chaiken MR. Drugs and predatory crime. In: Tonry $\mathrm{M}$, Wilson JQ editors. Drugs and crime.. Chicago: University of Chicago Press; 1991. pp. 241-320. 